\title{
The epidemiology and small-scale spatial heterogeneity of urinary schistosomiasis in Lusaka province, Zambia
}

\author{
Christopher Simoonga ${ }^{1}$, Lawrence N. Kazembe ${ }^{2}$, Thomas K. Kristensen ${ }^{3}$, Annette Olsen ${ }^{3}$, \\ Chris C. Appleton ${ }^{4}$, Patricia Mubita ${ }^{5}$, Likezo Mubila ${ }^{5}$ \\ ${ }^{1}$ Ministry of Health, P.O. Box 30205, Lusaka, Zambia; ${ }^{2}$ Mathematical Sciences Department, Chancellor \\ College, University of Malawi, P.O. Box 280, Zomba, Malawi; ${ }^{3}$ DBL - Centre for Health Research and \\ Development, Faculty of Life Sciences, University of Copenhagen, Thorvaldsensvej 57, DK-1871 \\ Frederiksberg C, Denmark; ${ }^{4}$ School of Biological and Conservation Sciences, University of KwaZulu-Natal, \\ P/Bag X10, Dalbridge 4014, South Africa; ${ }^{5}$ Department of Biological Sciences, University of Zambia, P.O. \\ Box 32379, Lusaka, Zambia
}

\begin{abstract}
In line with the aims of the "National Bilharzia Control Programme" and the "School Health and Nutrition Programme" in Zambia, a study on urinary schistosomiasis was conducted in 20 primary schools of Lusaka province to further our understanding of the epidemiology of the infection, and to enhance spatial targeting of control. We investigated risk factors associated with urinary schistosomiasis, and examined small-scale spatial heterogeneity in prevalence, using data collected from 1,912 schoolchildren, 6 to 15-year-old, recruited from 20 schools in Kafue and Luangwa districts. The risk factors identified included geographical location, altitude, normalized difference vegetation index (NDVI), maximum temperature, age, sex of the child and intermediate host snail abundance. Three logistic regression models were fitted assuming different random effects to allow for spatial structuring. The mean prevalence rate was $9.6 \%$, with significance difference between young and older children (odds ratio $(\mathrm{OR})=0.71 ; 95 \%$ confidence interval $(\mathrm{CI})=0.51-0.96)$. The risk of infection was related to intermediate host snail abundance $(\mathrm{OR}=1.03 ; 95 \% \mathrm{CI}$ $=1.00-1.05)$ and vegetation cover $(\mathrm{OR}=1.04 ; 95 \% \mathrm{CI}=1.00-1.07)$. Schools located either on the plateau and the valley also differed in prevalence and intensity of infection for moderate infection to none $(\mathrm{OR}=1.64 ; 95 \% \mathrm{CI}=1.36$ 1.96). The overall predictive performance of the spatial random effects model was higher than the ordinary logistic regression. In addition, evidence of heterogeneity of the infection risk was found at the micro-geographical level. A sound understanding of small-scale heterogeneity, caused by spatial aggregation of schoolchildren, is important to inform health planners for implementing control schistosomiasis interventions.
\end{abstract}

Keywords: urinary schistosomiasis, spatial epidemiology, Bayesian analysis, Zambia.

\section{Introduction}

Schistosomiasis, a disease caused by parasites of the genus Schistosoma, is currently estimated to infect at least 200 million people, among an estimated at-risk population of 779 million (Steinmann et al., 2006). Estimates further suggest that sub-

Corresponding author:

Christopher Simoonga

Ministry of Health, P.O. Box 30205, Lusaka, Zambia

Tel. +211 253053; Fax: +260 211253053

E-mail: simoongachris@yahoo.com
Saharan Africa bears a disproportionately high burden of the disease, with $85 \%$ of all schistosomiasis cases occurring in the region (Chitsulo et al., 2000). Two forms, urinary schistosomiasis caused by S. haematobium, and intestinal schistosomiasis caused by $S$. mansoni are endemic in sub-Saharan Africa. The current control strategy of schistosomiasis recommends provision of praziquantel in areas of high prevalence, especially through school health programmes or through (routine) primary health care services. Mass treatment repeated annually is advocated for schools where prevalence is over $50 \%$ 
to ensure that levels of infection are kept below those associated with severe morbidity (Hotez et al., 2008).

However, because of small-scale focality of the disease, implementation of any control strategy should understand where the population at risk is located for spatial targeting of limited resources, for efficient and cost-effective control (Brooker et al., 2002). The spatial variability of schistosomiasis is partly explained by a range of climatic, ecological and socioeconomic factors. Numerous geographical landscapes of varied characteristics, biotic and abiotic features affect survival and development of schistosome parasites and intermediate host snail populations. Socioeconomic and behavioural characteristics of human community such as water-contact behaviour, adequacy of water and sanitation shape the frequency of exposure to infected water (Appleton, 1978; Chandiwana et al., 1987).

This paper reports a cross-sectional study carried out in two districts of Lusaka province, Zambia, with the aim of furthering our understanding of the epidemiology of urinary schistosomiasis. Such knowledge is important for the "School Health and Nutrition Programme", and indeed the "National Bilharzia Control Programme" of the Ministry of Health $(\mathrm{MoH})$. Previous efforts under the School Health Programme to assess prevalence of schistosomiasis in the area used questionnaire-generated data (Lengeler et al., 2002), which assisted the delivery of praziquantel to primary schools in the province. However, experience in applying the questionnaire in this study indicated the need to carefully validate the tool in different epidemiological and sociocultural settings, as most lightly-infected individuals, without visible haematuria, were overlooked. Further, although haematuria is a key parameter for assessing urinary schistosomiasis, it can contribute to misdiagnosis as also other urinary tract infections present with this symptom. Careful validation in various community settings would improve both the sensitivity and specificity of the questionnaire rendering it more useful for monitoring the effectiveness of control programmes.
In this study, we investigated risk factors of urinary schistosomiasis. We also examined small-scale spatial heterogeneity in prevalence, an area less commonly explored despite spatial focality of the disease (Utzinger et al., 2003a, Brooker, 2007). Recent advances in spatial statistical tools have seen an increase in the application of spatial methodologies in analysing the prevalence of schistosomiasis and soil-transmitted helminths (Kristensen et al., 2001; Brooker et al., 2002; Raso et al., 2005; Brooker, 2007). We applied a random-effects spatial logistic model to account for spatial heterogeneity in prevalence, adjusting for age, sex and other explanatory variables.

\section{Materials and methods}

\section{Study area and design}

Field surveys were conducted in two districts, Kafue and Luangwa, in Lusaka province, Zambia (Fig. 1), after obtaining ethical clearance from the University of Zambia Ethics Committee.
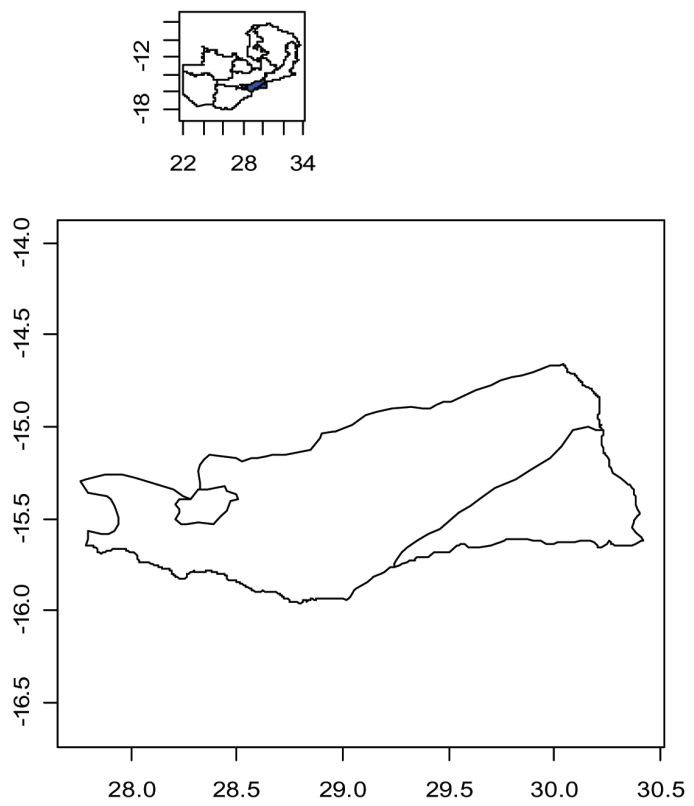

Fig. 1. Map of Zambia showing the study area (shaded region in the top plot), and expanded below. 
The two districts were selected on the basis of their ecological representativeness of the country in general (Abell et al., 1998; Brooker et al., 2002; Meteorology Department, 2003). In each of these districts 10 primary schools were selected. Approximately 100 schoolchildren, 6 to 15 -year-old, were recruited from each school in both districts.

The altitude and geographical location (longitude, latitude) of the surveyed schools were obtained from the archives of the Survey Department (2003). Further details of the study design are given elsewhere (Simoonga et al., 2007).

\section{Field data collection}

Data on S. haematobium prevalence and intensity were obtained using the quantitative filtration technique (Mott, 1984) to process and examine microscopically specimens prepared in duplicate for each urine sample that were collected about midmorning. Two laboratory technicians were trained to prepare and read the specimen filters. Both technicians read each specimen independently, which increased the sensitivity of the technique, particularly where egg counts were low (Barreto et al., 1990). All pupils found to be infected were treated with praziquantel (40 mg/kg body weight). Individual data sheets were used to collect ancillary information on each child examined.

In addition, data on intermediate host snails were obtained through field collections and laboratorybased species identification. The sampling of potential schistosomiasis transmission sites was done based on the proximity of the water-body to the respective primary school, i.e. the nearest likely infection source. These water points were also qualified by relevant local people as the most frequented water-contact points for both domestic purposes and/or by livestock.

The identified sites were geo-referenced with a hand-held global positioning system (GPS) device (Magellan Systems Corp., San Dimas, CA, USA) and this information was used to assess prevalence and abundance of intermediate host snails during the malacological surveys conducted before and after the rainy season. Two standardized snail scoops were used by two field operators during the snail surveys, each one allocated a duration of 15 min of scooping. Where scoops were not possible to use, for instance in muddy, semi-dry habitats, each operator handpicked snails for $15 \mathrm{~min}$.

Collected snails were placed individually in vials containing $10 \mathrm{ml}$ of water and exposed to light for two hours in order to induce cercarial shedding. Due to lack of facilities for species identification of the cercariae, this study used morphology and rhythmic vibrations to try and differentiate the shaded human cercariae from mammalian ones as described by Jordan and Webbe (1969) and Davis et al. (1972). Shedding snails were then placed in separate vials for species identification using field guides (Brown and Kristensen 1989; Danish Bilharziasis Laboratory, 1998).

\section{Climate data}

Climate data were downloaded in $1-\mathrm{km}$ image files from the website (http://edcdaac.usgs.gov/1kmhomepage.html). These images were captured by the Advanced Very High Resolution Radiometer (AVHRR) onboard National Oceanic and Atmospheric Administration (NOAA) polar-orbiting meteorological satellites (Cracknell, 1997). The images were calibrated into normalized difference vegetation index (NDVI) and mid-day earth surface temperature $\left(\mathrm{T}_{\max }\right)$ values using the ERDAS Imagine 8.5 (ERDAS, Atlanta, GA, USA) software for each decadal (10-day) interval between April 1992 and September 1993 and between February 1995 and January 1996.

\section{Statistical analysis}

The analysis focussed on the prevalence and intensity of infection. The intensity of infection was expressed as the geometric mean of egg counts. This was further categorised into four outcomes namely: (i) no infection (i.e. 0 eggs $/ 10 \mathrm{ml}$ of urine), (ii) light infection (1-100 eggs/10 ml of urine), (iii) moderate 
infection (101-400 eggs/10 $\mathrm{ml}$ of urine), and (iv) heavy infection ( $>400$ eggs $/ 10 \mathrm{ml}$ of urine) (Carabin et al., 2005). The data were further stratified by altitude (plateau for elevation of 601-1150 m and valley for $\leq 600 \mathrm{~m}$ ), sex (male, female) and age (6-9 years, $10-15$ years) and assessed for any significant variations. The $\chi^{2}$ test was used to explore for association between prevalence of infection and altitude, sex, age, and between intensity of infection and the same covariates. A $t$-test was used to determine differences in intensity, as measured by the geometric means of egg counts, between plateau and valley. The analyses were carried out in R ( $\mathrm{R}$ Development Team, 2007).

Three logistic regression models were developed to determine the relationship between infection outcome (positive or negative) and risk factors, i.e. environmental/ecological (altitude, NDVI, $\mathrm{T}_{\max }$ ), malacological (intermediate host snail abundance), and individual-level demographic covariates (sex, age). The first model fitted was an ordinary logistic regression model, assuming homogeneity in the infection rates. This is given by

$$
\operatorname{logit}\left(p_{i}\right)=
$$

$\beta_{0}+\beta_{1}$ age $+\beta_{2}$ sex $+\beta_{3}$ altitude $+\beta_{4} \mathrm{NDVI}+\beta_{5} \mathrm{~T}_{\max }+\beta_{6}$ snail (equation 1),

where $p_{i}$ is the probability of infection for child $i$, and $\beta_{i}, i=0, \Lambda, 6$ are regression parameters such that $\exp \left(\beta_{i}\right)$ are interpreted as odds ratios (ORs).

The second model was an extension of the first and included random effects $(u)$ to capture unstructured heterogeneity, i.e.

$$
\operatorname{logit}\left(p_{i}\right)=
$$

$\beta_{0}+\beta_{1}$ age $+\beta_{2}$ sex $+\beta_{3}$ altitude $+\beta_{4} \mathrm{NDVI}+\beta_{5} \mathrm{~T}_{\text {max }}+\beta_{6}$ snail $+u$ (equation 2).

The third model assumed spatially correlated random effects $(s)$ and is given by

$$
\operatorname{logit}\left(p_{i}\right)=
$$

$\beta_{0}+\beta_{1}$ age $+\beta_{2}$ sex $+\beta_{3}$ altitude $+\beta_{4} \mathrm{NDVI}+\beta_{5} \mathrm{~T}_{\max }+\beta_{6}$ snail $+s$ (equation 3 ).
The unstructured random effects, given by equation 2, were modelled by assuming exchangeable Gaussian processes, $u \sim N\left(0,1 / \tau_{u}\right)$, where $\tau_{u}$ is the precision parameter. The spatially correlated random effects are modelled by assigning an isotropic stationary Gaussian process with mean 0, and correlation function $1 / \tau_{u} \exp (-d / \phi)$ where $\tau_{s}$ is the precision parameter, $d_{r t}$ is the Euclidean distance between schools $r$ and $t$, with a spatial correlation decay between any two schools measured by $\phi$. The models were estimated using Bayesian inference via Markov chain monte Carlo (MCMC) simulation techniques. Given suitably chosen prior distributions for the unknown parameters, MCMC samples were drawn of all parameters by running 40,000 iterations. The first 5,000 samples were discarded as "burn-in", and every $35^{\text {th }}$ sample was thinned. The subsample of 1,000 was then summarized to provide point parameter estimates and corresponding Bayesian credible intervals (BCIs). We assigned the following priors:

(i) the fixed effects were assigned diffuse priors;

(ii) the precision parameters were assumed to follow a gamma distribution with parameters; and

(iii) the spatial correlation function was assumed to be distributed as an exponential function.

The three models were compared using the deviance information criteria (DIC), proposed by Spiegelhalter et al. (2002). The DIC is composed of the mean posterior deviance $\bar{D}$, which measures model fit and the effective number of parameters $p_{D}$, which represents model complexity. Small values of DIC imply a better-fitting model. All models were estimated in BayesX (Brezger et al., 2005). Model validation used receiver operating characteristics (ROC) curves analysis, a method recently used to validate regression models (Brooker et al., 2002), in which the proportion of "true positives" (sensitivity) is plotted against the proportion of "false negatives" (1-specificity) across a range of threshold values. One performance measure used in the ROC analysis is the area under the curve (AUC) of the ROC plot. A purely random model would be expected to be correct half of the time $(\mathrm{AUC}=0.5$ ), whereas a perfect model would be correct all the 
time (AUC $=1.0)$. We validated the ordinary model (model no. 1) against the random effects models (models nos. 2 and 3), and again between the spatially unstructured random effects and the spatially structured random effects models (model no. 2 and model no. 3, respectively).

After obtaining consent, a total of 2,040 schoolchildren, 6 to 15 years of age were enrolled into the study from the 20 selected primary schools in the two districts, Kafue and Luangwa of Zambia. Of these enrolled children, 1,912 (94\%) provided urine samples for parasitological examination, and hence this sample served as our final study cohort.

\section{Results}

\section{Prevalence and intensity of infection}

Table 1 shows a summary of the prevalence and intensity of infection of the schoolchildren from the
20 primary schools. The mean prevalence rate for the two districts was $9.6 \%$ (range $=0-36.1 \%$ ). The mean prevalence was slightly higher in Kafue district, although not significant, than that in Luangwa district $(10.9 \%$ versus $8.4 \%)$. The intensity of infection among positives had a mean of $31.4 \mathrm{eggs} / 10 \mathrm{ml}$ of urine (range $=0-120 \mathrm{eggs} / 10 \mathrm{ml}$ of urine). However there was a significant difference in the mean intensity of infection, with 40.2 (range $=3$ 53.1 ) eggs $/ 10 \mathrm{ml}$ of urine observed in Kafue district and 22.6 (range $=0-116.0$ ) eggs $/ 10 \mathrm{ml}$ of urine in Luangwa district.

Table 2 shows the relative number and percentage of schoolchildren, stratified by different intensity levels, and compares the overall geometric mean of $S$. haematobium egg counts between schoolchildren from plateau and valley schools. No significant difference in prevalence of infection was observed between the plateau and the valley for moderate infection to no infection. However, in the heavy

Table 1. Prevalence and intensity of urinary schistosomiasis infection in the 20 mixed-sex schools selected in the districts of Kafue and Luangwa in Zambia.

\begin{tabular}{|c|c|c|c|c|c|c|}
\hline District & School & Altitude of school & No. examined & No. positive & $\begin{array}{c}\text { Prevalence* } \\
(\%)\end{array}$ & $\begin{array}{c}\text { Geometric mean egg count } \\
(\text { eggs } / 10 \mathrm{ml})^{ \pm}\end{array}$ \\
\hline \multicolumn{7}{|l|}{ Kafue } \\
\hline 1. & Chilileka & Plateau & 94 & 16 & 17.0 & 120 \\
\hline 2. & Hachipilika & Plateau & 96 & 3 & 3.1 & 28.6 \\
\hline 3. & Kasaka & Plateau & 98 & 2 & 2.0 & 12.0 \\
\hline 4. & Lishiko & Plateau & 99 & 33 & 33.3 & 81.1 \\
\hline 5. & Muchuto & Plateau & 94 & 8 & 8.5 & 14.0 \\
\hline 6. & Nanduba & Plateau & 97 & 35 & 36.1 & 50.7 \\
\hline 7. & Siamikobo & Plateau & 91 & 1 & 1.1 & 3.0 \\
\hline 8. & Gota gota & Valley & 102 & 3 & 2.9 & 18.4 \\
\hline 9. & Kabwadu & Valley & 83 & 2 & 2.4 & 20.6 \\
\hline 10. & Mafungautsi & Valley & 92 & 2 & 2.2 & 53.1 \\
\hline \multicolumn{7}{|l|}{ Luangwa } \\
\hline 1. & Kakaro & Plateau & 91 & 2 & 2.2 & 16.7 \\
\hline 2. & Luangwa & Plateau & 85 & 2 & 2.4 & 3.6 \\
\hline 3. & Chirirwe & Valley & 102 & 9 & 8.8 & 12.6 \\
\hline 4. & Janeiro & Valley & 104 & 1 & 1.0 & 18.0 \\
\hline 5. & Kapoche & Valley & 102 & 4 & 3.9 & 7.8 \\
\hline 6. & Katondwe & Valley & 102 & 17 & 16.7 & 25.3 \\
\hline 7. & Kaunga & Valley & 81 & 11 & 13.6 & 4.7 \\
\hline 8. & Kavalamanja & Valley & 104 & 0 & 0 & 0 \\
\hline 9. & Mwalilia & Valley & 100 & 6 & 6.0 & 116.0 \\
\hline 10. & Mwavi & Valley & 95 & 28 & 29.5 & 21.6 \\
\hline
\end{tabular}

*Calculated as percentage of the positives from those who submitted urine samples

\pm Only positives were considered into the school geometric mean egg count 
Table 2. Schoolchildren from Luangwa and Kafue districts living within the two sampled ecological zones, plateau and valley, stratified by infection intensity. Values are numbers (\%) of children unless stated otherwise

\begin{tabular}{|c|c|c|c|}
\hline \multirow[t]{2}{*}{ Characteristics value* } & \multicolumn{2}{|c|}{ No. $(\%)$ of schoolchildren } & \multirow[t]{2}{*}{$\mathrm{P}$} \\
\hline & $\begin{array}{l}\text { Plateau region } \\
\quad(\mathrm{n}=669)\end{array}$ & $\begin{array}{l}\text { Valley region } \\
(\mathrm{n}=1243)\end{array}$ & \\
\hline \multicolumn{4}{|l|}{$\begin{array}{l}\text { Urinary schistosomiasis infection } \\
\text { intensity (eggs/10 } \mathrm{ml} \text { of urine): }\end{array}$} \\
\hline No infection $(0)$ & $571(85)$ & $1156(93)$ & ns \\
\hline Light infection (1-100) & $67(10)$ & $78(6)$ & ns \\
\hline Moderate infection (101-400) & $11(2)$ & $5(0.4)$ & ns \\
\hline Heavy infection $(>400)$ & $20(3)$ & $4(0.3)$ & 0.001 \\
\hline Geometric mean egg count $(95 \% \mathrm{CI}) \neq$ & $58(38$ to 87$)$ & $18(13$ to 26$)$ & 0.001 \\
\hline
\end{tabular}

*Comparison between regions was done using Chi-square test for different infection intensity levels or t-test for geometric mean egg counts

$\ddagger$ Only infection positive schoolchildren were included, (plateau, $\mathrm{n}=98$; valley, $\mathrm{n}=87$ ); $95 \% \mathrm{CI}=95 \%$ confidence interval

infection category significant differences in infection rates were observed. For infection intensity, given as geometric mean egg counts, significant differences were found between schoolchildren on the plateau (58 eggs/10 $\mathrm{ml}$ of urine, $95 \%$ confidence interval $(\mathrm{CI})=38-87 \mathrm{eggs} / 10 \mathrm{ml}$ of urine) and those from the valley $(18 \mathrm{eggs} / 10 \mathrm{ml}$ of urine; $95 \% \mathrm{CI}=13-26)$ at $\mathrm{P}<0.001$.

The model-building strategy considered the same fixed-effects covariates with a range of additional random effects, and proposed the use of DIC for model selection. Table 3 shows the DIC for the three estimated models. Model 2 had the lowest DIC and was therefore considered the best fitting one (DIC = 1730.2, 1592.0 for models 1 and 3, respectively, versus DIC $=1590.8$ in model 2 ). However, the difference, 1.2, between models 2 and 3 implies that the two models cannot be distinguished and are equally well fitting. The posterior estimates of fixed effects, based on model 2, are given in Table 4. The risk of urinary schistosomiasis was found to be lower in children aged 5 to 9 years compared to

Table 3. Deviance information criteria (DIC) for three logistic regression models fitted to the data.

\begin{tabular}{lccc}
\hline Model & $\bar{D}$ & $p_{D}$ & DIC \\
\hline Ordinary (fixed effects) logistic model & 1716.02 & 7.08 & 1730.2 \\
Unstructured heterogeneity effects & 1544.84 & 22.96 & 1590.8 \\
Spatially structured effects & 1549.16 & 21.43 & 1592.0 \\
\hline
\end{tabular}

those aged 10 to 15 years $(\mathrm{OR}=0.69 ; 95 \% \mathrm{BCI}=$ $0.50-0.95)$. Children living on the plateau were associated with increased risk of urinary schistosomiasis compared to those in the valleys $(\mathrm{OR}=1.64$; $95 \% \mathrm{BCI}=1.36,1.96)$. Increased risk was also observed between urinary schistosomiasis and NDVI (the mean Dec-Nov biannual composites of NDVI) with OR $=1.04$ (95\% BCI = 1.00-1.07), and a similar positive relationship was obtained between snail abundance and risk of infection $(\mathrm{OR}=1.03$; $95 \%$ BCI $=1.00-1.05)$.

\section{Spatial heterogeneity in prevalence of infection}

Figure 2 shows spatial random effects of 20 communities from where the sampled children were drawn. Evidently, the risk of infection varied with location. The regression residuals derived from model 2 were assessed for spatial autocorrelation, through the use of a semi-variogram. Figure 3 indicates a lack of spatial correlation among the 20 communities, thus all possible variability in infection has been adequately explained by the random effects logistic regression model (equation 2).

Figure 4 shows the ROC analysis results for the three models fitted above. The solid black reference line represents equal trade-offs between sensitivity and specificity of the prediction modelling. The reference line has an area under the ROC curve (AUC) 
Table 4. Variables and fixed effects in the univariate logistic model and multiple spatial logistic model (model 2) of urinary schistosomiasis. Given are odds ratios (OR) and 95\% confidence intervals (CI).

\begin{tabular}{|c|c|c|c|c|}
\hline \multirow[t]{2}{*}{ Variable } & \multicolumn{2}{|c|}{ Univariate } & \multicolumn{2}{|c|}{ Multivariate } \\
\hline & OR $(95 \% \mathrm{CI})$ & $\mathrm{P}$ & OR $(95 \% \mathrm{CI})$ & $\mathrm{P}$ \\
\hline \multicolumn{5}{|l|}{ Sex } \\
\hline Male & $0.79(0.58,1.07)$ & 0.132 & $1.19(0.87,1.63)$ & 0.267 \\
\hline Female & 1.00 & & 1.00 & \\
\hline \multicolumn{5}{|l|}{ Age } \\
\hline 5-9 years & $0.73(0.54,1.00)$ & 0.051 & $0.71(0.51,0.96)$ & 0.023 \\
\hline $10-15$ years & 1.00 & & 1.00 & \\
\hline \multicolumn{5}{|l|}{ Altitude } \\
\hline Plateau & $1.20(1.09,1.32)$ & 0.01 & $1.64(1.36,1.96)$ & 0.01 \\
\hline Valley & 1.00 & & 1.00 & \\
\hline NDVI & $0.93(0.91,0.96)$ & 0.001 & $1.04(1.00,1.07)$ & 0.034 \\
\hline $\mathrm{T}_{\max }$ & $0.95(0.91,1.00)$ & 0.045 & $0.98(0.93,1.04)$ & 0.303 \\
\hline Snail abundance & $1.26(1.11,1.43)$ & 0.001 & $1.03(1.00,1.05)$ & 0.043 \\
\hline
\end{tabular}

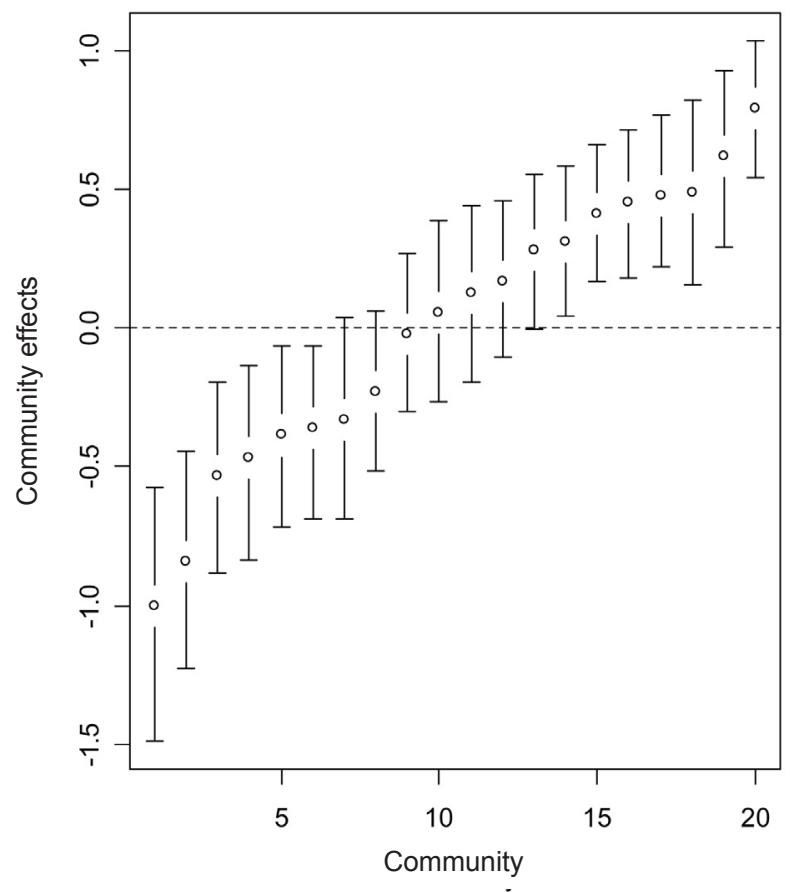

Fig. 2. A caterpillar plot showing spatial random effects (circles) at the 20 communities samples were collected. Error bars show $95 \%$ Bayesian credible intervals. The horizontal dotted line shows the zero effect.

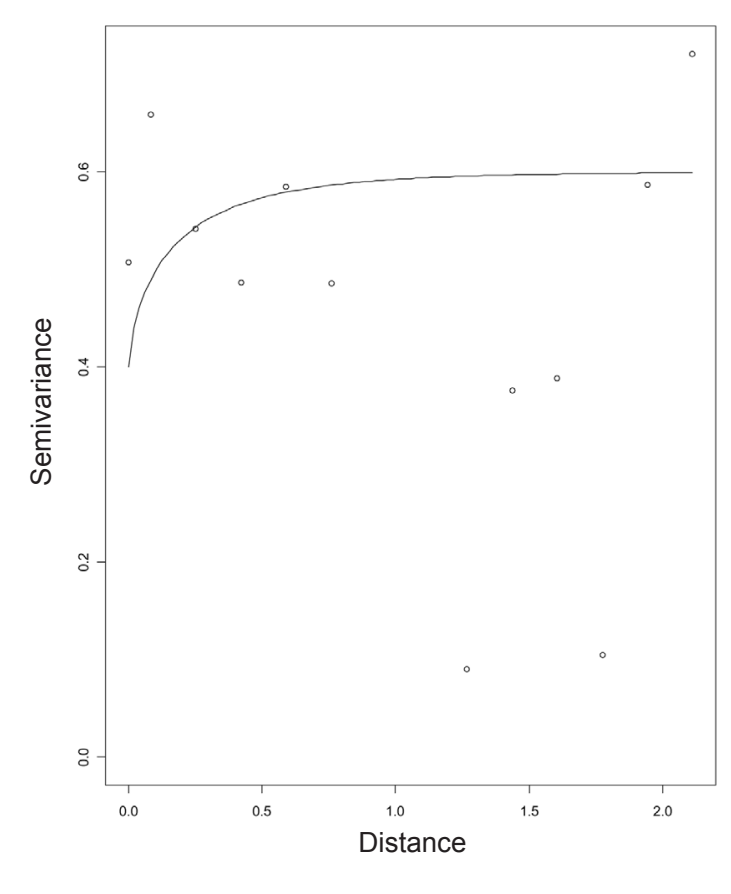

Fig. 3. A semivariogram of deviance residuals obtained from the random effects logistic regression model (model 2). 


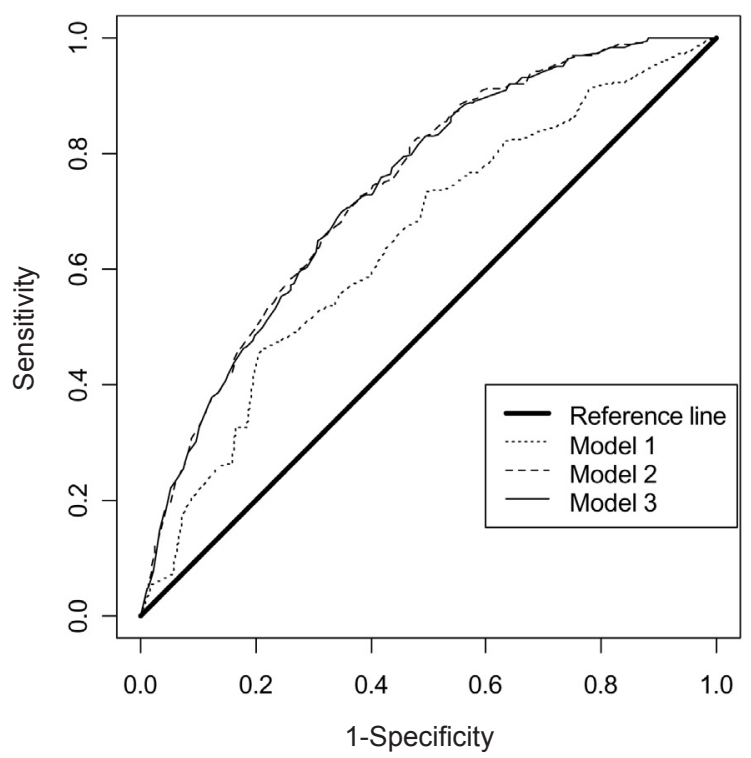

Fig. 4. Receiver operating characteristics (ROC) analysis for the ordinary and random effects models of prevalence of urinary schistosomiasis. The solid black line is the reference line which represents equal trade-off.

equal to 0.50 . The AUC for the ordinary logistic regression model (model 1) is 0.61 , while for the two random effects models the AUC are 0.74 for both models 2 and 3. The overall predictive performance of random effects models was higher than the ordinary model. The AUC of 0.74 in model 2 implies that the prevalence of urinary schistosomiasis infection is as high as $73.8 \%$.

\section{Discussion}

The study examined small-scale heterogeneity in prevalence of infection from a sample of 1,912 schoolchildren drawn from 20 schools in Kafue and Luangwa districts, Zambia. We found evidence of heterogeneity in risk of infection at a micro-geographical level. Studies dealing with quantification of such small-scale heterogeneities and their use in targeting control initiatives are relatively few (Utzinger et al., 2003a), despite the focal nature of schistosomiasis (Brooker and Michael, 2000; Brooker et al., 2002). Substantial variation in expo- sure to schistosomiasis, even within endemic communities, has been reported in Brazil (Bavia et al., 2001), Côte d'Ivoire (Raso et al., 2005) and Kenya (Clennon et al., 2004), but such evidence has been lacking in Zambia (Michelson, 1989). Heterogeneity, caused by spatial aggregation of schoolchildren, would inform appropriate adjustments in planning control interventions and targeting of limited resources. The search for risk factors, i.e. behavioural and environmental determinants will have to be more localized if the extent of their influence on transmission dynamics should impact on control programmes.

With regard to prevalence, our study found a relatively low rate of infection, with no significant differences between the two districts. This is due to the fact that high prevalence rates in both districts were found in schools located within the same altitude range without major climate differences. Our observation of non-significant variations in prevalence rates amongst the surveyed schools compares well with Mukaratirwa et al. (1999), who reported similar transmission intensities in this climatic region in Zimbabwe. However, significant differences were observed between young and older children, and between children from valleys and the plateau. These observed differences are associated with the increased-risk behaviour of older schoolchildren who frequently contacted schistosome-infested water for both domestic and livestock purposes (Mungomba et al., 1995). We observed, during the dry season, that schoolchildren in the schools on the plateau tended to have a higher degree of water-contact than those in the schools of the valley. The reason is that the water sources for domestic and livestock purposes remain relatively unlimited due to perennial rivers flowing through such as the Zambezi River. The national schistosomiasis control programme should consider provision of safer alternative water sources for both domestic and livestock purposes, during the dry season when the only available water sources are collected pools that are often infested with $S$. haematobium-infected snails. Public health interventions tailored to improving the water 
sources should be complemented with effective health education in both schools and communities on participatory hygiene and sanitation (Utzinger et al., 2003b, Singer and Castro, 2007).

Regarding environmental factors of infection, our results indicate that NDVI and the abundance of intermediate host snails (Bulinus globosus) have a significant influence on the transmission of urinary schistosomiasis in Zambia. Malone et al. (2001) observed that successful development of an intermediate host snail-parasite system within a given ecological setting was significant for maintaining schistosomiasis transmission in a community.

Our observation also compared well with Mukaratirwa et al. (1999) who reported a range of 128 to 160 for NDVI and $20^{\circ}$ to $21^{\circ} \mathrm{C}$ for $\mathrm{T}_{\max }$ as being optimal for the development and maintenances of a $B$. globosus-S. haematobium system, and explained urinary schistosomiasis transmission in a similar climatic environment in Zimbabwe. However, there were no significant variations observed between the schools on the plateau and in the valley. This is because schools that had relatively higher infection risk and snail abundance were found in the same altitude range with no significant differences in temperature.

From the point of control, it is important that an integrated approach within a primary health care system is adopted by ensuring that infection source reduction through the control of intermediate host snails is combined with chemotherapy for morbidity control. Our study also emphasize the need for comparing environmental predictors at finite spatial scales if micro-epidemiological mapping of infection risk should be of value in control programmes. Furthermore behavioural factors, such as watercontact activities, are particularly important for small-spatial scale risk mapping.

Our results show that the risk of infection with urinary schistosomiasis is heterogeneous, and therefore there is need to undertake further localized studies, based on questionnaires, to establish exposure risk factors. For example, we intend to determine water-contact patterns and then combine these with malacological surveys. Further to this, instead of using schools as spatial points, it is suggested that future studies focus on households in high-risk areas. This would avoid spatial aggregation, but allow appropriate finite-scale spatial mapping, and thus offer further insight into the micro-epidemiology of schistosomiasis, and therefore help to tailor control programmes at local and relevant levels.

\section{Acknowledgements}

The study was undertaken as part of a Ph.D. research programme for the first author and was made possible by generous financial and technical support from DBL (Danish Bilharziasis Laboratory now the DBL - Centre for Health Research and Development, University of Copenhagen, Denmark). The first author is also grateful to the Zambian $\mathrm{MoH}$ for the support during this study. The processing of the risk models would not have been possible without the technical support from Professor John B. Malone's Pathobiological Sciences laboratory at Louisiana State University. To the University of Zambia, Department of Biological Sciences, and most importantly all the primary schoolchildren that participated in the study, thank you very much for your invaluable contributions.

\section{References}

Abell R, Underwood E, Olson D, Dinerstein E, 1998. Freshwater ecoregions of Africa. The WWF-US Conservation Science Programme. Maps of the Expert Workshop, Cape Town, South Africa.

Appleton CC, 1978. Review of literature on abiotic factors influencing the distribution and life-cycles of bilharziasis intermediate host snails. Malacol Rev 11, 1-25.

Barreto ML, Smith DH, Sleigh AC, 1990. Implications of faecal egg count variation when using the Kato-Katz method to assess Schistosoma mansoni infections. Trans $\mathrm{R}$ Soc Trop Med Hyg 84, 554-555.

Bavia ME, Malone JB, Hale L, Dantas A, Marroni L, Reis R, 2001. Use of thermal and vegetation index data from earth observing satellites to evaluate the risk of schistosomiasis in Bahia, Brazil. Acta Trop 79, 79-85.

Brezger A, Kneib T, Lang S, 2005. BayesX: analysing 
Bayesian structured additive regression models. J Stat Soft $14,11$.

Brooker S, 2007. Spatial epidemiology of human schistosomiasis in Africa: risk models, transmission dynamics and control. Trans R Soc Trop Med Hyg 101, 1-8.

Brooker S, Hay SI, Bundy DAP, 2002. Tools from ecology: useful for evaluating infection risk models? Trends Parasitol 18, 70-74.

Brooker S, Michael E, 2000. The potential of geographical information systems and remote sensing in the epidemiology and control of human helminth infections. Adv Parasitol 47, 245-288.

Brown DS, Kristensen TK, 1989. A field guide to African freshwater snails. Southern African species. Publication of the Danish Bilharziasis Laboratory, Denmark.

Carabin H, Marshall CM, Joseph L, Riley S, Olveda R, McGarvey ST, 2005. Estimating the intensity of infection with Schistosoma japonicum in villagers of Leyte, Philippines. Part I: a Bayesian cumulative logit model. The schistosomiasis transmission and ecology project (STEP). Am J Trop Med Hyg 72, 745-753.

Chandiwana SK, Christensen NØ, Frandsen F, 1987. Seasonal patterns in the transmission of Schistosoma haematobium, S. mattheei and S. mansoni in the highveld region of Zimbabwe. Acta Trop 44, 433-444.

Chitsulo L, Engels D, Montresor A, Savioli L, 2000. The global status of schistosomiasis and its control. Acta Trop 77, 41-51.

Clennon JA, King CH, Muchiri EM, Kariuki HC, Ouma JH, Mungai P, Kitron U, 2004. Spatial patterns of urinary schistosomiasis infection in highly endemic area of coastal Kenya. Am J Trop Med Hyg 70, 443-448.

Cracknell AP, 1997. The Advanced Very High Resolution Radiometer. Taylor and Francis Publication, London, UK.

Danish Bilharziasis Laboratory, 1998. A field guide to African freshwater snails. Introduction. DBL Publication, Charlottenlund, Denmark.

Davis A, Farooq M, Hairston NG, Macdonald G, McMullen DB, Oliver LJ, Ritchie LS, Stirewalt MA, Uemura K, Wright WH, 1972. Epidemiology and control of schistosomiasis (bilharziasis). World Health Organization. Published by S Karger, AG 25, Geneva, Switzerland.

Hotez PJ, Brindley PJ, Bethony JM, King CH, Pearce EJ, Jacobson J, 2008. Helminth infections: the great neglected tropical diseases. J Clin Invest 118, 1311-1321.

Jordan P, Webbe G, 1969. Human schistosomiasis. Publication of the William Heinemann Medical Books Ltd. London Jordan and Webbe, London, UK.

Kristensen TK, Malone JB, McCarroll JC, 2001. Use of satellite remote sensing and geographical information systems to model the distribution and abundance of snail intermediate hosts in Africa: a preliminary model for Biomphalaria pfeifferi in Ethiopia. Acta Trop 79, 73-78.

Lengeler C, Utzinger J, Tanner M, 2002. Questionnaires for rapid screening of schistosomiasis in sub-Saharan Africa. Bull World Health Organization 80, 235-242.

Malone JB, Yilma JM, McCarroll JC, Erko B, Mukaratirwa S, Xinyu Z, 2001. Satellite climatology and environmental risk of Schistosoma mansoni in Ethiopia and east Africa. Acta Trop 79, 59-72.

Meteorological Department, 2003. Annual climate report. Ministry of Agriculture Food and Fisheries. Government of the Republic of Zambia.

Michelson EH, 1989. Schistosomiasis in Zambia: an historical overview and review of the literature. Afr J Med Sci 18, 269-281.

Mott KE, 1984. Schistosomiasis: new goal. World Health Organization, Geneva, Switzerland.

Mukaratirwa S, Malone JB, McCarroll JC, Kristensen TK, 1999. Satellite surveillance, geographical information systems and the seasonal suitability of environment for the development of the snail-parasite system of urinary and intestinal schistosomiasis in Zimbabwe. Proceedings of the Workshop on Medical and Veterinary Malacology in Africa, Harare, Zimbabwe. Publication of the Danish Bilharziasis Laboratory, Copenhagen, Denmark, pp. 265271.

Mungomba LM, Madsen H, Chandiwana SK, Magadza CH, 1995. Distribution, seasonal population fluctuations and infection rates of schistosome intermediate-host snails at Lake Kariba, Siavonga, Zambia. Proceedings of Status of Research on Medical Malacology in Relation to Schistosomiasis in Africa, Zimbabwe, pp. 89-105.

Raso G, Matthys B, N'Goran EK, Tanner M, Vounatsou P, Utzinger J, 2005. Spatial risk prediction and mapping of Schistosoma mansoni infections among schoolchildren living in western Côte d'Ivoire. Parasitology 131, 97-108.

Simoonga C, Kristensen TK, Olsen A, Appleton CC, Mubila 
L, 2007. Mapping and modelling urinary schistosomiasis in Zambia, using geographical information systems and remote sensing. Proceedings of Workshop on African Freshwater Malacology, Kampala, Uganda. Publication of the Danish Bilharziasis Laboratory, Copenhagen, Denmark, pp. 63-78.

Singer BH, de Castro MC, 2007. Bridges to sustainable tropical health. Proc Natl Acad Sci USA 104, 16038-16043.

Spiegelhalter DJ, Best NG, Carlin BP, van der Linde A, 2002. Bayesian measures of model complexity and fit (with discussion). J R Stat Soc B 64, 1-34.

Steinmann P, Keiser J, Bos R, Tanner M, Utzinger J, 2006.
Schistosomiasis and water resources development: systematic review, meta-analysis, and estimates of people at risk. Lancet Infect Dis 6, 411-425.

Survey Department, 2003. Annual survey report. Ministry of Lands. Government of the Republic of Zambia.

Utzinger J, Bergquist R, Xiao SH, Singer BH, Tanner M, 2003b. Sustainable schistosomiasis control-the way forward. Lancet 362, 1932-1934.

Utzinger J, Müller I, Vounatsou P, Singer BH, N’Goran EK, Tanner M, 2003a. Random spatial distribution of Schistosoma mansoni and hookworm infections among schoolchildren within a single village. J Parasitol 89, 686-692. 